\title{
PSYCHOMETRIC ASSESSMENT OF DENTAL PHOBIA AND TREATMENT DEFERRAL AMONG UNDERGRADUATE STUDENTS OF HEALTH SCIENCES: A CROSS SECTIONAL STUDY
}

\author{
Khizra Rehman', Atiya Abdul Karim', Sidra Mohiuddin ${ }^{1 凶}$, Abeeha Batool Zaidi'
}

\begin{abstract}
OBJECTIVE: To determine the association of dental anxiety and mental health among undergraduate students of health-care profession with delays in seeking dental treatment.

METHODS: This cross-sectional study was performed on 400 undergraduate students attending Ziauddin College of Dentistry, Karachi, Pakistan. The sample was selected through non-probability convenience sampling from age group between 18-24 years old. A validated structured questionnaire was used to measure dental anxiety through modified dental anxiety scale, anxiety induced consumption patterns and dental treatment avoidance. Data was analyzed through SPSS version-22.

RESULTS: Out of 400 students, 296 (74\%) were females and 104 (26\%) were males; $223(55.8 \%)$ were $\leq 20$ years old. About $52.2 \%(n=209)$ consumed fizzy drinks and $49.5 \%(n=198)$ used to brush their teeth once daily. Thirty-five percent $(n=139)$ never visited the dentist for check-up and $38.2 \%(n=153)$ reported low dental fear. High, moderate \& low level of anxiety was observed in $22(14.1 \%), 86(55.1 \%) \& 48(30.8 \%)$ students with deferral in dental treatment as compared to I5 (6.2\%), I $24(50.8 \%)$ I05 (43.0\%) students with no deferral in dental treatment respectively $(p<0.05)$. Majority of females $(64.7 \%)$ as compared to males $(35.3 \%)$ had delayed treatment due to dental phobia $(\mathrm{p}<0.0 \mathrm{I})$. Moderate \& mild depression was observed in six $(3.9 \%) \& 25(16 \%)$ students with deferral in dental treatment as compared to $15(6.2 \%) \& 34$ (13.9\%) students with no deferral in dental treatment respectively.
\end{abstract}

CONCLUSION: A significant association was noted between dental anxiety and negative dental-health seeking behaviors, while stress had no significant association with deferral.

KEY WORDS: Dental Health Services (MeSH); Mental Health (MeSH); Dental Anxiety $(\mathrm{MeSH})$; Dental Care $(\mathrm{MeSH})$.

THIS ARTICLE MAY BE CITED AS: Rehman K, Karim AA, Mohiuddin S, Zaidi AB. Psychometric assessment of dental phobia and treatment deferral among undergraduate students of health sciences: a cross sectional study. Khyber Med Univ J 2020;12(3):216-20. DOI: 10.35845/kmuj.2020.18992.

\section{INTRODUCTION}

A nxiety is a period of at least six months with prominent tension, worry and feelings of apprehension, about every-day events and problems.' The terms dental fear and anxiety are particularly connected and usually used within the literature. A difference between "normal" dental fear and "pathologic" dental anxiety is; normal fear is a physiological, behavioural, and sensitive response to a feared object or situation but pathological anxiety is considered as, the loss of the original signal operate of the anxious response, which will be triggered by objectively harmless things. ${ }^{2}$ Dental discomfort may additionally influence dental specialist relationship with their patients and misguide appropriate finding of the genuine dental issue. ${ }^{3}$ Patients with
I. Department of Community and Preventive Dentistry, Ziauddin College of Dentistry, Karachi, Pakistan.

Email『: sidra.mohiuddin@zu.edu.pk

Contact \#: +92-332-34I I 242

Date Submitted: February 04,2019

Date Revised: July 19,2020

Date Accepted: July 19,2020

anxiety can lead to xerostomia induced dental caries, worsening of their oral health with tendency of substance abuse. ${ }^{4}$

Through literature search, it was revealed that studies from other parts of the world have also shown greater prevalence of dental anxiety among undergraduate students. A study performed in a university in Norway stated that dental students have a significantly lower level of dental anxiety as compared to psychology and biology students. Senior dental students also have less dental anxiety than junior dental students. ${ }^{5}$ A similar study conducted in Malaysia further demonstrates that dental students have a considerably low level of dental anxiety as compared with medical and pharmacy students. ${ }^{2}$ The study in south India showed that females and younger subjects were more anxious than others. Subjects who were anxious had also postponed their dental visit. Participants who had negative dental experience were more anxious which was perceived higher towards extraction procedure. ${ }^{6}$ Studies conducted on students in various cities of Saudi Arabia showed females had more dental anxiety and depression as compared to males respectively. ${ }^{7,8}$ Increased levels of psychological distress was found more in medical students than dental students ${ }^{9}$ while severe anxiety was found in 34\% of dental students. ${ }^{10}$ Tooth drilling and local anaesthetic injection was considered to 


\section{TABLE I: DESCRIPTIVE ANALYSIS OF SOCIO DEMOGRAPHIC AND MENTAL HEALTH VARIABLES $(\mathbf{N}=400)$}

\begin{tabular}{|c|c|c|c|}
\hline \multicolumn{2}{|c|}{ Variables } & Frequency & Percentage \\
\hline \multirow{2}{*}{ Age (years) } & $\leq 20$ & 223 & 55.8 \\
\hline & $>20$ & 177 & 44.2 \\
\hline \multirow{2}{*}{ Gender } & Male & 104 & 26 \\
\hline & Female & 296 & 74 \\
\hline \multirow{3}{*}{$\begin{array}{l}\text { Frequency of teeth } \\
\text { brushing }\end{array}$} & Occasionally & 86 & 21.5 \\
\hline & Once a day & 198 & 49.5 \\
\hline & Twice a day & 116 & 29 \\
\hline \multirow{4}{*}{ Dental visit } & Never & 139 & 34.8 \\
\hline & With- in last three months & 87 & 21.7 \\
\hline & With- in 6-12 months & 118 & 29.5 \\
\hline & More than a year & 56 & 14 \\
\hline \multirow{3}{*}{$\begin{array}{l}\text { Mental Health } \\
\text { (Depression) }\end{array}$} & Normal & 329 & 82.3 \\
\hline & Mildly depressed & 59 & 14.7 \\
\hline & Moderately depressed & 12 & 03 \\
\hline \multirow{3}{*}{ Dental Anxiety } & Low dental anxiety & 153 & 38.2 \\
\hline & Moderate dental anxiety & 210 & 52.5 \\
\hline & High dental anxiety & 37 & 9.3 \\
\hline \multirow{5}{*}{$\begin{array}{l}\text { Eating and Chewing } \\
\text { habits of study subjects }\end{array}$} & Sugary items & 121 & 30.2 \\
\hline & Junk food & 105 & 26.2 \\
\hline & Fizzy drinks & 209 & 52.2 \\
\hline & Smoked tobacco & 53 & 13.2 \\
\hline & Chewable tobacco & 37 & 9.2 \\
\hline
\end{tabular}

TABLE II: ASSOCIATION AMONG DEFERRAL IN DENTAL TREATMENT WITH SOCIO DEMOGRAPHIC VARIABLES, DENTAL ANXIETY AND DEPRESSION $(\mathrm{N}=400)$

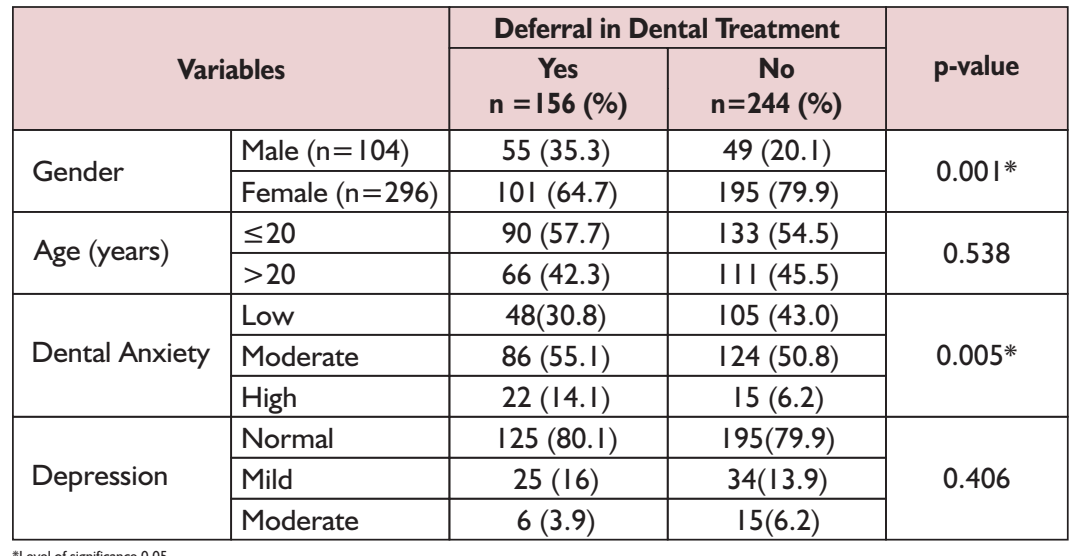

be the most fearful dental procedure among undergraduate students.

Dental anxiety is common as proven in a research done in India among $(n=500)$ undergraduate medical, dental and nursing students. Most of the medical and nursing students exhibited high dental anxiety which accounted a response rate of $82 \%$. A similar study was performed in Islamabad, Pakistan among students of "' different universities with the different dental anxiety scale which confirmed high level of prevalence of dental anxiety among the students. ${ }^{12}$ Another cross sectional study was performed by public medical university in Karachi, using standardized questionnaire of Dental Anxiety Scale (DAS), reported that dental anxiety was more common in students of medical and pharmacy. Aforementioned studies showed that female students had higher score for dental anxiety. ${ }^{11-13}$ Anxiety is exceedingly common and cause impressive depression and sickness trouble. To strengthen this general medical issue, numerous people with mental disorder stay untreated although the treatment exists but the gap is still present. ${ }^{14}$ In undergraduate population certain sub-groups have an overall higher prevalence of emotional wellbeing issues, which is predictable with investigations of the general population. Male students are at a greater risk for suicide, however female showed positive results for real depression and tension issue. ${ }^{15}$ Also several studies showed eating problems pattern among individuals with major depression and increase intake of sugary item and junk foods in the people with emotionally distress. ${ }^{16-20}$

Hence, dental anxiety has been a major barrier in utilization of dental treatment. Moreover, availability of limited data regarding dental anxiety, dental treatment deferral and its association with gender and age developed the need to perform research. Furthermore, in current study, assessment of mental health in addition to Modified Dental Anxiety Scale (MDAS) scale for assessing dental anxiety was performed. Thus the aim of the study was to determine the association of dental anxiety and mental health among undergraduate health care professionals with delays in seeking dental treatment.

\section{METHODS}

This cross-sectional study was conducted at medical, pharmacy and dental college of Ziauddin university hospital in Karachi, Pakistan from March to August 2018. Approval of the study was obtained from the Principal of the Dental College. A total of 400 undergraduate students with an age of 18-24 years were enrolled through non probability convenience sampling. The selection criteria of the study subjects were as follow: all undergraduate students from the aforementioned university, students who were present at 
the day of data collection, students who gave consent to be a part of this study. Sample size was calculated by using open epi sample size calculator by keeping confidence interval at $95 \%$, power of test at $80 \%$ and level of significance at 0.05 . Data collection was based upon the assessment of socio-demographic variables, dental anxiety, self-reporting measure of treatment deferral and selfrating depression scale using a valid structured questionnaire. ${ }^{12,13}$ Selected undergraduate students from all three colleges were approached during their self-study time, first of all, purpose of the research study was clearly explained to participants and later upon their consent, study questionnaires were distributed among students. Dental anxiety was assessed through Modified Dental Anxiety Scale (MDAS); a five item tool comprising on two sections assessing anxiety before treatment and three during treatment on five point Likert scale ranging from I (not anxious) to 5 (very anxious). A total score of dental anxiety was sum of all five items, range 5 to 25 and was categorized as: highly anxious with the cut-off of 19 or above and 10 is for low fear dentally phobic. ${ }^{2 !}$

Furthermore, the evaluation of mental health of the study participants as the tendency of depression was also assessed by using a depression scale based upon 20 questions related to negative experiences of participants in last several days. ${ }^{22}$ The cumulative scores ranging from 25 to 100 ; which was further categorized as normal with a score from 25 till 49 , mild depression at score from 50 till 59, moderate depression with a score from 60 till 69 , whereas 70 and above was considered as severely depressed. In addition, students were also asked about socio demographic variables such as gender, age, year of study, about their last visit to the dentist/hygienist as well as about their brushing habits.

All the data was entered using SPSS version 22. Descriptive statistics were reported as frequencies and percentages. Chi-square test was applied to analyze association between treatment delay and dental anxiety. The level of significance was considered as less than 0.05 .

\section{RESULTS}

Out of 400 undergraduate subjects, 177 (44.2\%) were aged above 20 years while 223 (55.8\%) were less than 20 years old. Gender wise distribution of study subjects showed 296 (74\%) females and $26 \%(n=104)$ males.

On asking about oral hygiene habits like frequency of teeth brushing; subjects who brushed once a day were 198 (49.5\%) while II 6 (29\%) brushed their teeth twice a day and about 86 (21.2\%) mentioned occasionally. Furthermore, reporting about visit to the dentist; 139 $(34.8 \%)$ subjects had never visited dentist, while $87(21.8 \%)$ subjects visited within three months, II8 $(29.5 \%)$ visited within a year and 56 (14\%) more than a year. Rest details of mental health, anxiety, and eating habits are given in Table I.

Moreover, statistically significant result was achieved among gender with deferral in dental treatment due to anxiety $\mathrm{p}$-value $=0.00 \mathrm{I}$. Males who were anxious and delayed their dental treatment were $35.3 \%(n=55)$ while in females $64.7 \%(n=101)$ deferred dental treatment. Also, there was a significant relationship between dental anxiety and delaying treatment ( $\mathrm{p}$ value $=0.005$ ) [Table II].

\section{DISCUSSION}

Dental anxiety is one of the real alarms in the daily schedule clinical practice that should be managed for the best possible oral healthcare. The present study was performed to examine the dental anxiety among undergraduates. We found gender of the study subjects to be associated with anxiety induced delays in dental treatment as more than two third of females $(64.7 \%)$ were missing their dental appointments due to dental phobia in comparison to males $p$-value $=0.00 \mathrm{I}$. However, the age of study participant did not have any relationship with anxiety associated treatment deferral $p$-value $=0.538$.

Our study also showed a positive association between dental anxiety and avoidance of dental treatment, this is supported by an existing research. ${ }^{23} \mathrm{~A}$ comparison verified that the mean MDAS score of present study subjects were similar to findings reported by Jordanian undergraduate with the $\mathrm{p}$ value $=0.03$ and Universities students of Islamabad ( $p$ value $<0.05$ ). ${ }^{3,12}$ Another study was conducted in Denmark on Danish adults which also verified that women are more likely to become anxious than men by a ratio of 2 to I. $^{3,13,24}$ Physiological feelings known with stress, discouragement, fear, social fear are across the board in females, and these might be associated with dental anxiety. ${ }^{25}$ As indicated by this information, it tends to be said that females are influenced more by negative environments than men since they have higher social cognition. This nervousness particularly influences their psychological thinking process which affects their readiness to observe certain behavior.

The findings of current study verified like those found in past studies that females have a tendency to be more restless than men and indicated higher DAS score. ${ }^{26}$ Unlike other studies our study did not find any relationship between depression and dental treatment deferral p-value (0.406). Some studies shows that patients who have a lower capacity to endure emotional and physical depression may have larger amounts of dental consideration related anxiety and nervousness and even dental fear, and in addition related with avoidance of dental care. ${ }^{27,28}$

Furthermore, we also probed study subjects about their consumption patterns when they feel low or tensed. Our study found higher preference towards intake of fizzy drinks during times of stress among males and females who consumed fizzy drinks at $50 \%$ and $53 \%$. Eating junk food was rated second common choice with similar pattern in females and males $27.9 \%$ and $31.1 \%$ respectively. Overall stress induced tobacco consumption was quite higher among males with smoked tobacco being taken up at $18.3 \%$ and chewable tobacco at $7.7 \%$. Contrary to this, $21 \%$ of the female population was using tobacco products for relieving their stress, which was still higher as there were more females in this study. 
However, our study reported the eating or drinking preferences of the students during stress time, but it was lacking in terms of measuring the magnitude of consuming unhealthy diets.

In addition to this, non-probability sampling nature of this study must have introduced some selection biases. Apart from this, we had selected quota of study participants from different departments of one center, which was able to bring diversity to an extent. However, limiting the data collection to one single center was another downside since individuals of higher income strata enrolled in this center and their eating preferences would be quite different from health sciences students in state university (from low income strata).

\section{CONCLUSION}

Results of our study show that gender has significant role in developing dental anxiety. Anxiety further lead to stress induce negative behaviors for seeking dental care which ultimately result in delays and /or prolonging in dental treatments from patients side as well as missed dental appointments by them. Therefore, in order to improve dental treatment care and reduce the chances of anxiety induced treatment deferral within the dental visits; dentist can identify the persons, counsel and treat them accordingly.

\section{REFERENCES}

I. World Health Organization (WHO). The ICD-I0 classification of mental and behavioral disorders: diagnostic criteria for research world health organization; 1993. [Accessed on: January 10, 2019]. Available from URL: https://www.who.int/ classifications/icd/en/bluebook.pdf.

2. Gunjal S, Pateel DG, Parkar S. Dental anxiety among medical and paramedical undergraduate students of Malaysia. Int J Dent 2017;2017:4762576. DOI:10. II55/2017/4762576.

3. Al-Omari WM, Al-Omiri MK. Dental anxiety among university students and its correlation with their field of study. J Appl Oral Sci 2009; 17(3):199-203. DOI: 10.1590

\section{/SI678-775720090003000I3.}

4. Kisely S. No mental health without oral health. Can J Psychiatry 2016;6I(5):277-82. DOI: 10.1 I77/ 0706743716632523.

5. Storjord HP, Teodorsen MM. Dental anxiety among university students at the University of Tromsø: A quantitative study [dissertation]. Norway: Tromsø Univ;20I3. [Accessed on: January 10, 2019]. Available from URL: https://munin. uit.no/bitstream/handle/ /0037/925 4/thesis.pdf?sequence $=$ I \&isAllowe $d=y$.

6. Appukuttan D, Subramanian S, Tadepalli A, Damodaran LK. Dental anxiety among adults: an epidemiological study in South India. N Am J Med Sci 2015;7(1):13-8. DOI: $10.4103 / 1947-27 \mid 4.150082$

7. Zaini R, Anjum F, Dahlawi H. Assessment of depression among applied medical science college students at Taif University: A Questionnaire Survey. J Psychiatry 20I8;2I(I): I00043I. DOI: 10. 4I72/2378-5756.100043I.

8. Sghaireen MG, Zwiri A, Alzoubi IA, Qodceih SM, AL-Omiri MK. Anxiety due to dental treatment and procedures among university students and its correlation with their gender and field of study. Int J Dent 20I3;20I3:647436. DOI:I0. | I55/2013/647436.

9. Aboalshamat K, Hou XY, Strodl E. Psychological well-being status among medical and dental students in Makkah, Saudi Arabia: A crosssectional study. Med Teach 2015;37(Suppl I):S75-8I. DOI: 10.3109/0142I59X.2015.1006612.

10. Basudan S, Binanzan N, Alhassan A. Depression, anxiety and stress in dental students. Int J Med Educ 2017;8:179-86. DOI: 10.5।16/ ijme.5910.b961.

II. Thomas M, Kumar V, Sooraparaju SG, Mathew T, Kumar A, Ealla KK. Dental anxiety among dental, medical, and nursing students in India and its correlation with their field of study. J Int Oral Health 2016;8(8):860-4. DOI: 10.2047/ jioh-08-08-05.

12. Attaullah AA. Prevalence of dental anxiety among university students in Islamabad, Pakistan. J Khyber Coll Dent 20 I I I (2):7I-7.

13. Zarah S, Majeed MM, Imtiaz A. Dental Anxiety among the Students of Public Sector Medical Universities of Karachi. J Dent Oro Surg 20I6; I (2):I-4. DOI: 10. 19104/jdos.2016.111.

14. Kohn R, Saxena S, Levav I, Saraceno B. The treatment gap in mental health care. Bull World Health Organ 2004;82(I I):858-66.

I5. Hunt J, Eisenberg D. Mental health problems and help-seeking behavior among college students. J Adolesc Health 2010;46(I):3-10. DOI: $10.1016 / \mathrm{j} . j a d o h e a l t h$. 2009.08.008.

16. Cardi V, Leppanen J, Treasure J. The effects of negative and positive mood induction on eating behaviour: A meta-analysis of laboratory studies in the healthy population and eating and weight disorders. Neurosci Biobehav Rev 20I5;57:299-309. DOI: 10 . I0I6/j.neubiorev.20I5.08.01I.

17. Kim JY, Kang HL, Kim DK, Kang SW, Park YK. Eating habits and food additive intakes are associated with emotional states based on EEG and $H R V$ in healthy Korean children and adolescents. J Am Coll Nutr 2017;36(5):335-4I. DOI: 10. I080/073I5724.2017.128I774.

18. Koski M, Naukkarinen H. Severe obesity, emotions and eating habits: a case-control study. BMC Obes 2017;4:2. DOI: 10.1I86/s40608016-0138-9.

19. Meng X, D'Arcy C. Comorbidity between lifetime eating problems and mood and anxiety disorders: Results from the Canadian community health survey of mental health and well being. Eur Eat Disord Rev 2015;23(2): 156-62. DOI: 10.1002/erv.2347.

20. Moore CF, Sabino V, Koob GF, Cottone P. Neuroscience of compulsive eating behavior. Front Neurosci 2017; I I:469. DOI: 


\section{I0.3389/fnins.20I7.00469.}

21. Hagqvist $O$, Tolvanen M, Rantavuor K, Karlsson L, Karlsson H, Lahti S. Short term longitudinal changes in adult dental fear. Eur J Oral Sci 20|8; | 26(4):300-6

22. Dunstan DA, Scott N, Todd AK. Screening for anxiety and depression: reassessing the utility of the Zung scales. BMC Psychiatry 2017;17(I):329. DOI: 10.1186/ s|2888-0| 7-|489-6.

23. Cohen SM, Fiske J, Newton JT. The impact of dental anxiety on daily living. $\mathrm{Br}$ Dent J 2000;189(7):38590. DOI: I0.1038/sj.bdj.4800777.
24. Moore R, Birn H, Kirkegaard E, Brødsgaard I, Scheutz F. Prevalence and characteristics of dental anxiety in Danish adults. Community Dent Oral Epidemiol 1993;2I(5):292-6. DOI: $10.1 \mathrm{III/j} .1600-0528.1993$. tb00777.x.

25. Locker D, Poulton R, Thomson WM. Psychological disorders and dental anxiety in a young adult population. Community Dent Oral Epidemiol 200I;29(6):456-63. DOI: I 0.1034/j. I600-0528.200I . 290607.x.

26. Stabholz A, Peretz B. Dental anxiety among patients prior to different dental treatments. Int Dent J 1999
Apr;49(2):90-4. DOI: I0.IIII/ j.1875-595x.1999.tb005।4.x.

27. Addicks SH, McNeil DW, Randall CL, Goddard A, Romito LM, Sirbu C, et al. Dental Care-Related Fear and Anxiety: Distress Tolerance as a Possible Mechanism. JDR Clin Trans Res 20I7;2(3):304-II. DOI: 10.1177/2380084417691962.

28. Halonen H, Salo T, Hakko $H$, Räsänen $\mathrm{P}$. The Association between dental anxiety, general clinical anxiety and depression among Finnish university students. J Oral Health Dent Manag 20I4;13(2): 320-5.

\section{AUTHORS' CONTRIBUTIONS}

Following authors have made substantial contributions to the manuscript as under:

KR: Acquisition of data, drafting the manuscript, approval of final version to be published.

AAK: Study concept, analysis \& interpretation of the data, drafting the manuscript, approval of final version to be published.

SM: Study design, critical review, approval of final version to be published.

ABZ: Acquisition, analysis \& interpretation of the data, drafting the manuscript, approval of final version to be published.

Authors agree to be accountable for all aspects of the work in ensuring that questions related to the accuracy or integrity ofany part of the work are appropriately investigated and resolved.

CONFLICT OF INTEREST

Authors declared no conflict of interest GRANT SUPPORT AND FINANCIAL DISCLOSURE NIL

\section{DATA SHARING STATEMENT}

The data that support the findings of this study are available from the corresponding author upon reasonable request

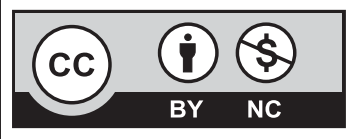

This is an Open Access article distributed under the terms of the Creative Commons Attribution-Non Commercial 2.0 Generic License.
KMUJ web address: www.kmuj.kmu.edu.pk

Email address: kmuj@kmu.edu.pk 